\title{
Study on the Policy Dilemma and Solution Strategies of General Aviation Industry Development in China
}

\author{
Hu Chengwei, Zhang Liang* \\ Guangzhou Civil Aviation College, Guangzhou, 510000 \\ *corresponding author: 25267764@QQ.com
}

Keywords: Dilemma, Solution, Aviation

\begin{abstract}
The paper puts forward the importance of the development of general aviation industry policy under the "new era", and analyzes the current difficulties in the development of general aviation industry policy from six aspects: policy management mechanism and policy system, policy goal setting and policy stability. To address the above issues, it proposes the theoretical and practical significance of strengthening performance evaluation of general aviation industry policies under the "new era” .
\end{abstract}

\section{The Importance of China's General Aviation Industry Policy for Constructing Systems under the "New Era"}

Comrade Xi Jinping pointed out in his report on the Nineteenth Congress that after long-term efforts, socialism with Chinese characteristics has entered a new era. This is a new historical orientation for the development of China [1]. In the "new era", there will be major and even turning-point changes in the two basic aspects of China's general aviation industry supply and demand. This kind of change means that the development of the general aviation industry with its main features of quantity and scale expansion in the past has been fully released. The difficulty of this traditional industrial development model will gradually increase in the future. From the perspective of supply-side structural reforms, China's general aviation industry must not only focus on quantitative growth and technological development, but also pay attention to the fair market environment of the aviation industry and the encouragement of competition so as to realize the general aviation industry around the industry. The quality of structure, quality, efficiency, benefits, and personalization are qualitatively improved. To achieve this goal, we must take the concept of supply-side reform as the guide, increase policy research to promote the development of the general aviation industry, and establish a systematic and comprehensive policy system of various types to ensure a qualitative leap in the general aviation industry.

(1) A Sound Policy System is an Important Tool for Promoting the Transformation of the Navigation Industry Structure under the "New Era"

At present, the main contradiction in the operation of China's general aviation industry is that the supply side has not played its due role in the formation of industrial structure and industrial transition. The balance of supply and demand in the new phase of industrial growth has not yet been established, and the quality and benefits of growth in the navigable industry have decreased. . To change these problems, we must rely on a well-developed industrial policy system to achieve transformation and upgrading of the general aviation industry structure from the supply and demand processes. A well-developed industrial policy plays an important role in promoting general aviation industry structural specialty: First, a systematic and sound policy system helps to change the overall quality of the general navigation industry. The quality is not high, the low end of the industrial value chain, the industrial structure is not excellent, the industry added Low value of the status quo; Second, the system of sound policy body is conducive to changing the traditional industries in the field of traditional demand, the pace of growth is apparently slow, a large number of emerging needs are suppressed is difficult to be released and meet the status quo; Third, the system of sound policy system will help change the new Technology and new methods are not enough to change the status quo that can't bring about the change of magnitude in industrial development. Fourth, the systematic and perfect policy system helps to change the status quo of industrial planning, 
investment is still disorderly, and the lack of industrial innovation and development thinking.

(2) A sound policy system is an important tool for building a market system for the general aviation industry in the "new era".

At present, the market system of general aviation industry in China has not been formed. In the process of marketization of the navigation industry, administrative power occupies a very important position, so that excessive administrative intervention has evolved into a market for general aviation industry development and a general aviation industry. Market operation is flawed. To change these problems, we must rely on a well-developed industrial policy system to achieve a general aviation industry market system from general aviation market construction and general aviation market operations. A well-developed industrial policy plays an important role and significance for constructing a market system for the general aviation industry. First, a well-developed policy system helps to change the status quo of the narrow financing channels and the imperfect investment and financing environment for general aviation industry development. Second, a systematic and sound policy system helps to change the current situation of imperfect and unsystematic tax policies in the general aviation industry. Third, a systematic and sound policy system helps to change the non-standard general aviation industry standard system and the lack of enterprise entry and exit mechanisms. The status quo; Fourth, the system of sound policy system is conducive to changing the general aviation industry market supervision is not strict, the industry is generally not high self-regulation capacity of the current situation.

(3) A Perfect Policy System is an Important Tool for Promoting the Upgrading and Upgrading of the Navigation Industry Chain under the "New Era"

At present, the perfect ground chain of the general aviation industry system in China is not completely formed. The existing industrial chain is formed spontaneously. Many problems that have arisen in the development of industrial clusters have failed to explain and the theoretical support system has lag behind seriously [2]. In order to realize leapfrog development in quality, the general aviation industry must create a full industrial chain support system from aircraft design and manufacturing to personnel training. In order to change these problems, we must rely on a well-developed industrial policy system to achieve a systematic and comprehensive general aviation industry chain from the perspectives of industrial chain cultivation and development. A well-developed industrial policy has an important role and significance for building a navigable industrial chain: First, a well-developed policy system helps to change the relevance and technology of the main business chain of the existing navigation industry, and it lacks a clear division of labor between the industry and the industry. The status quo of industrial characteristics; Second, a systematic and sound policy system helps to change the general convergence of the general aviation industry structure, it is difficult to form the status quo of the public mechanism to promote effective interaction and mutual promotion of the industry; Third, the system of sound policy system helps to change the general The market environment of the aviation industry is not ideal, and the industrial clusters lack the status quo of action norms and rules. Fourth, a systematic and sound policy system helps to change the current low value-added general aviation industry chain and limited knowledge and technology diffusion.

(4) A perfect policy system is an important tool for the development of a soft environment for the development of the navigation industry in the "new era".

The current soft environment that promotes the development of China's general aviation industry has not been realized. The development of the navigable industry is more concerned with the construction of hardware such as infrastructure construction, aircraft quantity, and enterprise increments, while ignoring the soft environment such as laws and regulations, human resource protection systems, and enterprise service security systems that play an important role in industrial development. To change these issues, we must rely on a well-developed industrial policy system to realize the two points of view from the establishment and improvement of the industrial soft environment. A well-developed industrial policy has an important role and significance for forming a general aviation industry soft environment: First, a systematic and sound policy system will help change the general aviation industry's lack of special laws and regulations that regulate the 
relationship between general aviation activities; It is a systematic and sound policy system that will help change the current state of lack of scientific system planning for general aviation-related infrastructure construction. Third, a systematic and sound policy system will help change the current status of general aviation's existing talent cultivation system and unbalanced industrial development; it is a systematic and sound policy system that will help change the current situation of the mismatch between the general aviation culture construction and the development of the general aviation industry.

\section{The Development Difficulties of China's General Aviation Industry Policies under the "New Era"}

Since August 2010, the State Council and the Central Military Commission issued the "Opinions on Deepening the Management Reform of Low-altitude Airspace in China", and the relevant national departments have taken active actions, and a series of policies and initiatives to promote the development of general aviation have come [3]. The related policies and measures to promote the development of the general aviation industry are also more and more specific. According to incomplete statistics, from 2010 to the present, the State Council, national ministries and commissions, civil aviation bureaus, and local governments have issued policies to promote the development of the general aviation industry that have reached hundreds. The introduction of these policies has strongly supported the development of the national and local general aviation industry and has played a significant role in guiding the development of the industry. However, despite the current series of policies that have achieved certain results in promoting the development of the general aviation industry, there are still many problems in the setting of policy objectives or in the management, implementation, and effectiveness of policies, mainly in the following areas. Aspects:

(1) Systematic match between policy management mechanism and policy is not high

China's current general aviation management system is still dominated by separate management and vertical management, showing obvious characteristics of administrative regions. It is characterized by a unified central policy, a competitive regional policy, and parallel military management policies. In this form, it will inevitably involve multiple government departments at the same level, and an effective coordination mechanism must be established between multiple departments and different regions. However, because such inter-departmental coordination mechanisms have not been established, the various management entities have become independent, resulting in lack of overall planning for general aviation industry policies, weak systems, and even contradictions, which in turn affect the overall layout of the industry. Lag behind the development of the industry.

(2) The matching of policy objectives and policy stability and continuity is not high

The general aviation industry has its own development cycle characteristics, which requires that the industrial policy maintains certain continuity and stability within the cycle. However, due to uncertainties and confusion in the setting of targets in China's general aviation industry, the stability of China's general aviation industry policy has been poor. The unclear understanding of how the general aviation industry develops has led to frequent policy changes and poor continuity. This has affected not only the effectiveness of policies, but also policy executors and policy objects, and has lost the confidence in policies.

(3) The matching of policy objectives and policy orientation is not high

Industrial policy serves to achieve industrial development goals, and the orientation of industrial policies directly affects the realization of industrial development goals. China's general aviation industry policy goal has been quite clear, that is, to improve the general aviation industry development quality services. However, China's current navigable industrial policy tends to be biased towards waste. Firstly, the policy focused on industrial scale development and light industry quality improvement, resulting in insufficient gravitational attraction for the general aviation industry; second, policy-oriented major projects and improvement of light industrial soft environment of large enterprises resulted in insufficient development potential of general aviation industry; Focusing on policy orientation and focusing on the support of the traditional market and 
the development of the emerging markets, the general aviation industry has a narrow market space. Fourth, it focuses on the prevention of specific problems in the direction of industrial policies, resulting in constant development of the general aviation industry.

(4) The degree of matching between policy system and policy development model is not high

China's general aviation industry must achieve a qualitative leap from factor input to innovation-driven development. Therefore, a comprehensive system of industrial policies and policies needs to be established to support the new development model of general aviation industry. However, China's current policy is not systematic and targeted, and it is difficult to become a support for the transformation and development of the general aviation industry. First, a policy system to promote the general aviation industry, including comprehensive financial policies, taxation policies, financial support policies, and science and technology development policies, has not yet been established, making the general aviation industry a policy blind spot in the development process and affecting industrial upgrading. Second, there are many guiding policies for general aviation industry at the macro level of development, and there are few micro-policy areas that are directed at specific areas. This is to make it difficult to refer to macro-level planning for specific problems, which can easily lead to differences in understanding. Perform the difference.

(5) The timeliness of the policy is inconsistent with the status quo and trends of industrial development.

The timeliness of the policy means that any policy is formulated for specific problems under certain conditions of time and space, and changes in time and space conditions will cause the policy to lose its effectiveness [4]. The lagging behind of a considerable portion of the current general aviation industry policy in China is relatively serious, and it is not well matched with the general aviation industry development status and future trends, and it is difficult to become the real driving force for the development of the industry. The first is that some of the navigation industry policies continue to implement some of the planned economic system. This is not only difficult to adapt to the new trend of market economy development in the new era, but also difficult to adapt to the new needs of the general aviation industry development in the new era; second, some of the navigation industry The policy has indeed played a positive and effective role in promoting industrial development when it was just introduced. However, with the changes in the external environment of industrial development, its effectiveness has begun to weaken or even disappear completely due to various reasons, which has become a constraint to the development of the industry.

(6) The degree of matching between the scientific nature of policy formulation and the effectiveness of policy implementation is not high

The scientific nature of policy formulation and the effective implementation of policies complement each other. A scientific policy system can ensure smooth implementation of the policy. At present, the scientific nature of the current general aviation industry policy in China is still open to question. Specifically, one is that the scope of participation in the development of the navigable industry policy is not enough. The current management system determines that the navigable industrial policy seldom involves the involvement of departments outside the civil aviation authority. Even if it participates, it cannot dominate the direction of policy formulation, resulting in poor communication channels in the process of policy formulation; second, the level of research in the formulation of the navigable industry policy is not enough. At this stage of the general aviation industry policy formulation process, it is often formulated by relevant departments of the competent department of the industry. Although relevant experts and scholars are also involved in the formulation, participation is limited. It does not form an institutionalized mechanism for the formulation of industrial policies with extensive participation of experts, enterprises, and social organizations. These problems will inevitably lead to inefficiency in the implementation of industrial policies and cannot truly become intellectual support for industrial development.

\section{Theory and practical significance of performance evaluation of general aviation industry policy in the "new era"}

Given the new opportunities and challenges in China's general aviation industry under the "New 
Era" and the development difficulties of China's general aviation industry policy under the "New Era", it is urgent for China to promote general aviation industry policies with the aim of promoting the structural reform of the supply side of the general aviation industry. To systematically optimize and adjust, innovatively establish an industrial policy system that adapts to the laws and development requirements of the general aviation industry under the "new era", and guides, supports, and promotes the rapid development of the general aviation industry. Industrial policy has truly become a new engine and new driving force for the development of general aviation industry. However, to achieve a systematic and optimized adjustment of general aviation industry policies, the first task is to systematically sort out existing general aviation industry policies based on the perspective of supply-side structural reforms, and focus on policy formulation and policies for existing industrial policies. Implementation of the system, and the results of the three aspects of the system to conduct a systematic assessment, found that in what areas the policy adjustment is not enough or implementation is not in place, to find the underlying causes of the problem, to provide the basis for the optimization of industrial policy. Therefore, it has important theoretical and practical significance for the performance evaluation of general aviation industry policies.

(1) The theoretical significance of the research on the performance evaluation of general aviation industry policy

It is of great theoretical significance to carry out general aviation industry policy performance evaluation from the perspective of supply-side structural reforms. The first is to enrich the theoretical system of industrial policy assessment in China, provide a new perspective for industrial policy assessment, and conduct policies for other industries. The evaluation of effects provides a new theoretical basis; the second is the combination of quantitative methods and qualitative methods to carry out the logical and scientific assessment of the effects of industrial policies, providing a new interdisciplinary approach for industrial policy assessment and policy for other industries. The evaluation of effectiveness provides a new methodological basis. Third, it builds an industrial policy evaluation mechanism from the perspective of improving the efficiency of the general aviation industry, provides a new model for industrial policy assessment, and provides a new system basis for policy evaluation of other industries. .

(2) Practical Significance of General Aviation Industry Policy Performance Evaluation

It is of great practical significance to conduct general aviation industry policy performance evaluation based on the perspective of supply-side structural reforms. The first is to help improve the scientific development of general aviation industry policy, and ensure that policy makers are based on in-depth research and extensive analysis. Actually, the government formulates policies in a scientific and systematic way. Second, it helps to improve the efficiency of general aviation industry policy implementation trends, and ensures that policy makers grasp the effectiveness, efficiency, and efficiency of policies based on in-depth research and extensive analysis. The third is to help improve the reliability of general aviation industry policy adjustments and ensure that policy makers make scientific choices for the continuation, adjustment, and termination of existing policies based on in-depth research and extensive analysis.

\section{References}

[1]http://news.xinhuanet.com/2017-10/18/c_1121819978.htm

[2] Peishan Zhou. Research on sustainable development of industrial clusters in Foshan [D]. Huazhong University of Science and Technology, 2007.

[3] http://www.sohu.com/a/125035121_468748

[4] Xiaohui Ma. On the Timeliness of Public Policy: Taking the "plastic limit order” as an example [J]. Old District Construction, 2015(24): 42-44. 